\title{
PENGARUH PENDIDIKAN KESEHATAN MENGGUNAKAN MEDIA VIDEO DAN ALAT PERAGA TERHADAP PENGETAHUAN DAN SIKAP REMAJA PUTRI TENTANG PERSONAL HYGIENE PADA MASA MENSTRUASI DALAM LAYANAN HOMECARE DI DUSUN KUMBUNG WILAYAH KERJA PUSKESMAS KURIPAN KABUPATEN LOMBOK
} BARAT 2021

\author{
Winda Ayu Ningsih", Mutiara Rachmawati Suseno², Bq Yuni Fitri Hamidiyanti ${ }^{3}$ \\ ${ }_{123}$ Program Studi DIII Kebidanan Poltekkes Kemenkes Mataram, Indonesia \\ email:susenomutiara@gmail.com
}

\section{N F O A R T I K E L \\ Sejarah artikel: \\ Menerima 21 September 2020 \\ Revisi3 Oktober 2021 \\ Diterima 4 Oktober 2021 \\ Online 10 Oktober 2020}

\section{Kata kunci:}

video dan alat peraga, personal hygiene masa menstruasi.

\section{Keywords:}

video and tool aids, personal hygiene period of menstruation

\begin{abstract}
ABSTRAK
Latar Belakang : Angka insiden penyakit infeksi yang terjadi pada saluran reproduksi pada remaja (10-18 tahun), yaitu 35 sampai 42 persen serta dewasa muda (18-22 tahun) sebesar 27 hingga 33 persen. Misal, kurangnya tindakan merawat kebersihan organ reproduksi ketika menstruasi. Berdasarkan studi pendahuluan yang dilakukan di Desa Kumbung wilayah kerja Puskesmas Kuripan Lombok Barat, kepada 10 remaja putri secara wawancara didapatkan hasil 9 remaja putri belum pernah terpapar mengenai personal hygiene masa menstruasi da 1 orang sudah pernah terpapar tentang personal hygiene masa menstruasi.

Tujuan Penelitian : untuk mengetahui adanya pengaruh pendidikan kesehatan menggunakan media video dan alat peraga terhadap pengetahuan dan sikap remaja putri dalam personal hygiene masa menstruasi

Metode Penelitian : Jenis penelitian ini adalah Pre Experimental dengan desain One Group Pretest-Posttest. Populasi penelitian ini adalah remaja putri dengan jumlah sampel 30 orang. Analisis data yang digunakan dalam penelitian ini menggunakan analisis non parametrik wilcoxon.

Hasil Penelitian : Hasil nilai pengetahuan sebelum diberikan pendidikan kesehatan didapatkan remaja putrid memiliki tingkat pengetahuan dalam kategori cukup yaitu sebanyak 18 orang (60\%) dan sesudah diberikan pendidikan kesehatan didapatkan remaja putri banyak yang memiliki tingkat pengetahuan dalam kategori baik sebanyak 29 orang (97\%). Remaja putri sebelum diberikan pendidikan kesehatan memiliki sikap dalam kategori baik sebanyak 19 orang(63\%) dan sesudah diberikan pendidikan kesehatan remaja putrid yang memiliki sikap dalam kategori baik bertambah menjadi 27 orang (90\%). Setelah dilakukan uji statistic diperoleh nilai $\mathrm{p}$ value $=0,000$ atau $\mathrm{p}<\alpha=$ 0,05 , yang berarti ada pengaruh.

Kesimpulan : Terdapat pengaruh pendidikan kesehatan menggunakan media video dan alat peraga terhadap pengetahuan dan sikap remaja putri tentang personal hygiene masa menstruasi.
\end{abstract}

\section{ABSTRACT}

Background: Figures incidence of disease infection that occurs on the channel reproduction in adolescents (10-18 years), which is 35 to 42 percent and mature young (18-22 years old ) by 27 to 33 percent. For example, the lack of action to take care of the cleanliness of the reproductive organs during menstruation. Based on the study of preliminary are done in the village of Kumbung region work Puskesmas Kuripan West Lombok, to 10 teenage daughter in the interview obtained results of nine teenage 
daughter has not been exposed to the personal hygiene period of menstrual da one person had been exposed to about personal hygiene period of menstruation .

Objective research : to determine the effect of education of health using video media and means of props to the knowledge and attitude of adolescent daughter in personal hygiene period of menstruation

Methods of study : type of research this is the Pre Experimental to design one group pretest-posttest. The population of this study was young women with a sample of 30 people. Analysis of the data used in the research is to use analysis of non-parametric Wilcoxon

Results of Research: Results of the value of knowledge before it is given the education of health obtained teenage daughter has a level of knowledge in the category enough that as many as 18 people (60\%) and after a given educational health obtained teenage daughter many who have the level of knowledge in the category ba ik as many as 29 people $(97 \%)$ $R$ emaja daughter before given the education of health has the attitude in the category well as 19 people (63\%) and after a given educational health of adolescent daughter who has an attitude in the category of either grow into 27 people (90\%). Having done the test statistic obtained by value $p$ value $=0.000$ or $p<\alpha=0,05$, which means there is influence.

Conclusion: There is the influence of education of health using video media and means of props to the knowledge and attitude of adolescent daughters about personal hygiene period of menstruation.

\section{PENDAHULUAN}

Menurut WHO (World Health Organization), remaja merupakan penduduk dalam rentan usia 10-19 tahun, menurut Peraturan Materi Kesehatan RI Nomor 25 tahun 2014, remaja adalah penduduk dalam rentang usia 10-18 tahun dan menurut Badan Kependudukan dan Keluarga Berencana (BKKBN) tentang usia remaja adalah 10-24 tahun dan belum menikah. Jumlah kelompok usia 10-19 tahun di Indonesia menurut sensus penduduk 2010 sebanyak 43,5 juta atau sekitar $18 \%$ dari jumlah penduduk. Di dunia diperkirakan kelompok remaja berjumlah 1,2 milyar atau $18 \%$ dari jumlah penduduk dunia. ( BKKBN, 2011).

Berdasarkan data World Health Organization (WHO) tahun 2010, usia remaja (35\%-42\%) memiliki angka kejadian kejadian infeksi saluran reproduksi (ISR) tertinggi didunia, dan dewasa muda (27\%-33\%) angka prevalensi candidiasis $(25-50 \%)$, bacterialvaginosis $(20-40 \%)$ dan trichomoniasis (5-15\%). Indonesia terdapat 43,3 juta jiwa remaja putri berusia 10-14 tahun berperilaku hygiene sangat buruk berdasarkan data statistic di Indonesia tahun 2012. Indonesia memiliki iklim yang panas dan lembab, sehingga wanita Indonesia lebih rentan mengalami ISR (Priyoto., 2014).
Tahun 2010, berdasarkan data yang dihimpun dari Badan Pusat Statistik dan Badan Perencanaan pembangunan Nasional, remaja di Indonesia 63 juta beresiko melakukan perilaku yang tidak sehat. Angka insiden penyakit infeksi yang terjadi pada saluran reproduksi pada remaja (10-18 tahun), yaitu 35 sampai 42 persen serta dewasa muda (18-22 tahun) sebesar 27 hingga 33 persen. Misal, kurangnya tindakan merawat kebersihan organ reproduksi ketika menstruasi. Rahmatika (2010) dalam penelitiannya mengungkapkan bahwa faktor pemicu kasus ISR antara lain perilaku kurang dalam merawat hygiene ketika menstruasi sejumlah 30 persen, imunitas yang rendah sejumlah 10 persen, lingkungan buruk dan tata cara dalam penggunaan pembalut yang kurang tepat ketika menstruasi sejumlah 50 persen (Katarina, 2015). Kesehatan khususnya masalah hygiene merupakan pilar yang berpengaruh terhadap kualitas hidup sumber daya manusia yang dapat menyebabkan infertilitas pada wanita (Ali, Tazeen Saeed, 2017).

Masa remaja dapat dikatakan suatu fase perkembangan yang dinamis dalam kehidupan seseorang. Perubahan paling awal muncul yaitu perkembangan secara biologis. Salah satu tanda keremajaan secara biologis yaitu mulainya remaja mengalami menstruasi (Rahmawati, 2012). Menstruasi atau haid merupakan

Jurnal Kebidanan Vol. 10 No. 2 Oktober 2021 | 60 
perdarahan secara periodic dan siklik dari uterus, disertai pelepasan (deskuamasi) endometrium (Proverawati dan misaroh, 2009).

Kurangnya kesadaran Menstrual Hygiene dan perawatan selama mentruasi yang disebabkan oleh kurangnya pengetahuan, sikap dan perilaku yang berkaitan dengan mentruasi dan kebersihan mentruasi dapat mnimbulkan masalah bagi remaja. Sebuah studi yang dilakukan di Nagpur melaporkan bahwa hanya $36,95 \%$ dari gadis-gadis itu menyadari mentruasi sebelum menarche. Lebih dari tiga dari 10 gadis tidak menyadari tentang penyebab dan sumber perdarahan sedangkan mayoritas dari mereka bahkan mengetahui tentang penggunaan pembalut. (Anusree et al., 2014), dalam penelitiannya juga menggambarkan bahwa ada perawatan yang tidak tepat dan tidak memadai dalam praktek higienis saat mentruasi kalangan remaja perempuan.

Data survey kesehatan Reproduksi Remaja Indonesia (SKKRI) tahun 2007 menyatakan bahwa secara nasional remaja yang perilaku hygiene dengan benar sebesar 21,6\%. Hasil survey menunjukkan remaja yang terpapar informasi Pusat Informasi dan Konseling Remaja mencapai 28\%. Berarti hanya 28 dari 100 remaja yang akses dengan kegiatan informasi Kesehatan Reproduksi yang berkaitan dengan mentruasi.

Personal hygiene mentruasi pada remaja merupakan isu kritis sebagai determinan status kesehatan remaja yang akan berpengaruh dalam kehidupan masa tua. Buruknya personal hygiene mentruasi berpengaruh besar terhadap morbiditas dan komplikasi. Oleh karna itu, remaja harus dipersiapkan baik pengetahuan, sikap maupun tindakannya ke arah pencapaian reproduksi yang sehat.

Kelebihan menggunakan Media video yaitu dapat memberikan pesan yang dapat diterima lebih merata oleh siswa, sangat bagus menerangkan suatu proses, mengatasi keterbatasan ruang dan waktu, dapat diulang atau dihentikan sesuai kebutuhan, dan memberikan kesan yang mendalam, dapat mempengaruhi sikap siswa. (Rusman, 2012).

di beberapa Negara Maju, home care bukan merupakan sebuah konsep yang baru. Konsep ini telah dikembangkan oleh Wiliam Rathon sejak tahun 1859 di Liverpool yang dinamakan perawatan di rumah dalam bentuk kunjungan tenaga keperawatan ke rumah untuk mengobati pasien yang sakit dan tidak bersedia dibawa ke rumah sakit. Florence Nightingale juga melakukan perawatan di rumah dengan memberikan perawatan kepada pasien yang mengalami sakit terutama bagi pasien dengan status ekonomi rendah, kondisi sanitasi, kebersihan diri dan lingkungan dan gizi buruk sehingga beresiko terhadap berbagai jenis infeksi yang umum ditemukan dimasyarakat. Selain karna tidak bersedia dibawa ke rumah sakit, homecare juga bisa menjadi perawatan lanjutan dari rumah sakit yang sudah dalam rencana pemulangan (dishcharge planning) dan dapat dilaksanakan oleh perawat dari rumah sakit semula atau perawat komunitas atau tim keperawatan yang khusus menangani perawatan di rumah (Bukit, 2008).

Lisa Handayani, dkk (2020), dalam penelitiannya yang berjudul "Pengaruh Edukasi Melalui Media Video Dan Leaflet Terhadap Perilaku Personal Hygiene Pada Masa Menstruasi Remaja Di SMPN 2 Toili Kec. Mailong Kab. Banggai“ didapatkan hasil bahwa terjadi perubahan pemahaman pengetahuan, sikap maupun tindakan siswi ketika diberikan pemahaman bahwa pentingnya kebersihan diri pada saat menstruasi.

Andi Basniati, dkk (2020) dalam penelitiannya yang berjudul "pengaruh Video Learning Multimedia Terhadap Pengetahuan, Sikap dan Perilaku Menstrual Hygiene Pada Remaja Putri" dalam penelitian ini analisis data dengan uji Homogeneity of Variance dan uji Wilcoxon. Hasil uji statistic menunjukkan bahwa terdapat pengaruh video learning multimedia terhadap perubahan pengetahuan, sikap dan perilaku menstrual hygiene pada remaja putri.

Berdasarkan jumlah penduduk menurut jenis kelamin dan kelompok umur kabupaten / kota Lombok Barat tahun 2019, kelompok umur dengan rentang usia 10-14 tahun sejumlah 66.738 jiwa, dan rentang umur 15-19 tahun sejumlah 65.397 jiwa. (DIKES LOBAR, 2019).

Berdasarkan studi pendahuluan yang dilakukan di Desa Kumbung wilayah kerja Puskesmas Kuripan Lombok Barat, kepada 10 remaja putri secara wawancara didapatkan hasil 9 remaja putri belum pernah terpapar mengenai personal hygiene masa menstruasi da 1 orang 
sudah pernah terpapar tentang personal hygiene masa menstruasi.

Berdasarkan studi pendahuluan yang dilakukan di Dusun Kumbung Wilayah kerja Puskesmas Kuripan Lombok Barat, kepada 10 remaja putri secara wawancara didapatkan hasil 3 remaja putri sudah melakukan hygiene masa menstruasi dengan benar dengan mengganti softek 4-5 kali sehari, dan 7 dri 10 remaja putri masih menerapkan hygiene yang kurang baik, seperti belum mengetahui cara cebok yang baik, belum mengetahui cara penggunaan sabun vagina yang baik.

Berdasarkan latar belakang diatas maka peneliti tertarik untuk melakukan penelitian tentang "Pengaruh Promkes dengan Metode Vidio dan Alat Peraga Terhadap Pengetahuan dan Sikap Remaja Putri Dalam Personal Hygiene pada masa menstruasi di desa Kumbung Kuripan Lombok Barat pada tahun 2021"

\section{METODE}

Desain penelitian yang akan digunakan adalah Pre Experimental dengan pendekatan One Group Pretest-Posttest yaitu untuk mengetahui perbedaan dan perubahan pada nilai sebelum dan setelah dilakukan intervensi.8 Tempat yang digunakan dalam penelitian ini adalah di wilayah kerja UPT BLUD Puskesmas Kuripan serta dilakukan penelitian selama 1 minggu. Populasi dalam penelitian ini adalah seluruh remaja putrid yang berada di dusun Kumbung, desa Kuripan Utara. Sampel untuk penelitian ini adalah remaja putrid yang memenuhi kriteria inklusi dan eksklusi, serta bersedia menjadi responden dalam penelitian dan menyetujui informed consent pada hari pertama.

Teknik pengambilan sampel pada penelitian ini secara purposive sampling yaitu dengan cara pengambilan sampel yang berdasarkan atas suatu pertimbangan tertentu seperti sifat-sifat populasi ataupun ciri-ciri yang diketahui sebelumnya.8 Besar sampel dalam penelitian ini sebanyak 30 orang.

Dalam penelitian ini yang menjadi Variabel Independen adalah Pendidikan Kesehatan menggunakan media video dan alat peraga tentang Personal hygiene Masa Menstruasi. Sedangkan Variabel Dependen adalah pengetahuan dan sikap remaja putrid dalam personal hygiene masa menstruasi.

Penelitian ini menggunakan data Primer yang dilakukan secara langsung oleh peneliti untuk mengolah data penelitian di UPT BLUD Puskesmas Kuripan. Data dianalisis secara univariat dengan tabel distribusi frekuensi berdasarkan semua variabel, dan analisis bivariat dalam menguji hipotesi menggunakan uji Marginal Homogeneity (Uji Nonparametrik). 8 
HASIL

A. Identifikasi Karakteristik:

Tabel 4.1 Distribusi Responden Menurut Umur dan pendidikan di UPT BLUD Puskesmas Kuripan

\begin{tabular}{lcc} 
Karakteristik & $\mathbf{N}$ & $\mathbf{\%}$ \\
\hline Umur & & 20 \\
\hline $10-13$ tahun & 6 & 33,3 \\
\hline $14-16$ tahun & 10 & 46,7 \\
\hline $17-19$ tahun & 14 & 40 \\
\hline Pendidikan & 12 & 60 \\
\hline Pendidikan dasar (SD-SMP) & 18 & 0 \\
\hline Pendidikan menengah (SMA) & 0 & $\mathbf{1 0 0}$
\end{tabular}

(Sumber: Data Primer, 2018).

Berdasarkan tabel 4.1 diatas, didapatkan bahwa responden terbanyak adalah yang berumur 17-19 Tahun berjumlah 14 orang $(46,7 \%)$ dan responden terendah berumur 10-13 tahun sebanyak 6 orang $(20,0 \%)$. pendidikan responden terbanyak adalah pendidikan menengah (SMA) berjumlah 18 orang (60\%) dan Pendidikan Dasar berjumlah 12 orang (40\%).

\section{A. Pengetahuan dan sikap Remaja putri tengtang personal hygiene masa menstruasi Sebelum Dan Setelah Diberikan Pendidikan Kesehatan.}

Tabel 4.2Distribusi jumlah responden berdasarkan tingkat pengetahuan dan sikap remaja putri dalam personal hygiene masa menstruasi sebelum dan sesudah pendidikan kesehatan di UPT BLUD Puskesmas Kuripan Tahun 2021.

\begin{tabular}{lcccc} 
& \multicolumn{2}{c}{ Sebelum Pendidikan Kesehatan } & \multicolumn{2}{c}{ Setelah Pendidikan Kesehatan } \\
\cline { 2 - 5 } Pengetahuan & $\mathbf{n}$ & $\mathbf{\%}$ & $\mathbf{N}$ & $\mathbf{2}$ \\
\hline Baik & 7 & 23 & 1 & 37 \\
\hline Cukup & 18 & 60 & 0 & 0 \\
\hline Kurang & 5 & 17 & $\mathbf{3 0}$ & $\mathbf{1 0 0}$
\end{tabular}

\begin{tabular}{lcccc} 
& \multicolumn{2}{c}{ Sebelum Pendidikan Kesehatan } & \multicolumn{2}{c}{ Setelah Pendidikan Kesehatan } \\
\cline { 2 - 5 } Sikap & $\mathbf{n}$ & $\mathbf{\%}$ & $\mathbf{N}$ & $\mathbf{\%}$ \\
\hline Positive & 19 & 63 & 27 & 90 \\
\hline Negative & 11 & 37 & 3 & $\mathbf{3 0}$ \\
\hline \multicolumn{1}{c}{ Total } & $\mathbf{3 0}$ & $\mathbf{1 0 0}$ & $\mathbf{1 0 0}$
\end{tabular}

( Sumber: Data Primer, 2021 ).

Berdasarkan Tabel 4.2diatas sebelum diberikan pendidikan kesehatan didapatkan bahwa remaja putri di Dusun Kumbung banyak yang memiliki tingkat pengetahuan dalam kategori cukup yaitu sebanyak 18 orang (60\%).
Dan sesudah diberikan pendidikan kesehatan didapatkan bahwa remaja putri di Dusun Kumbung banyak yang memiliki tingkat pengetahuan dalam kategori baik yaitu sebanyak 29 orang (97\%).dan sebelum diberikan 
pendidikan didapatkan bahwa remaja putri di Dusun Kumbung banyak memiliki sikap dalam kategori positif yaitu sebanyak 19 orang $(63 \%)$. Dan sesudah diberikan pendidikan kesehatan didapatkan bahwa remaja putri di Dusun Kumbung banyak yang memiliki sikap dalam kategori positif yaitu sebanyak 27 orang $(90 \%)$.

\section{B. Pengaruh Pendidikan Kesehatan Tentang TTD Pada Kelas Ibu Hamil Terhadap Kepatuhan Ibu dalam Mengkonsumsi TTD.}

Tabel4.3 UjiMarginal Homogeneityterhadap pengetahuan remaja putrid tentang personal hygiene masa menstruasi sebelum dan setelah dilakukan pendidikan kesehatan menggunakan media video dan alat peraga tentang personal hygiene masa menstruasi di Dusun Kumbung Tahun 2021.

\begin{tabular}{cccccc}
\hline \multirow{2}{*}{ Pengetahuan } & \multicolumn{2}{c}{ Sebelum Penkes } & \multicolumn{2}{c}{ Setelah Penkes } & \multirow{2}{*}{ p-value } \\
\cline { 2 - 5 } & $\mathbf{n}$ & $\mathbf{0}$ & $\mathbf{N}$ & $\mathbf{0}$ & \\
\hline Baik & 7 & 23 & 29 & 97 & 0,000 \\
\hline Cukup & 18 & 60 & 1 & 3 \\
\hline Kurang & 5 & 17 & 0 & 0 \\
\hline Total & $\mathbf{3 0}$ & $\mathbf{1 0 0}$ & $\mathbf{3 0}$ & $\mathbf{1 0 0}$
\end{tabular}

\begin{tabular}{cccccc}
\hline \multirow{2}{*}{ Sikap } & \multicolumn{2}{c}{ Sebelum Penkes } & \multicolumn{2}{c}{ Setelah Penkes } & \multirow{2}{*}{ p-value } \\
\cline { 2 - 5 } & $\mathbf{n}$ & $\mathbf{0}$ & $\mathbf{N}$ & $\mathbf{0}$ & \\
\hline Positif & 19 & 63 & 27 & 90 & 0,000 \\
\hline Negative & 11 & 37 & 3 & 10 & \\
\hline Total & $\mathbf{3 0}$ & $\mathbf{1 0 0}$ & $\mathbf{3 0}$ & $\mathbf{1 0 0}$ & \\
\hline
\end{tabular}

( Sumber: Data Primer, 2018 ).

Berdasarkan hasil uji Marginal Homogenity diperoleh nilai signifikansi adalah 0,000. Nilai $\mathrm{p}<0,05$ maka dapat disimpulkan bahwa ada perbedaan yang signifikan antara tingkat pengetahuan remaja awal sebelum dan sesudah diberikan pendidikan kesehatan menggunakan media video dan alat peraga tentang personal hygiene masa menstruasi sehingga ada pengaruh pendidikan kesehatan menggunakan media video dan alat peraga tentang personal hygiene masa menstruasi terha tingkat pengetahuan remaja putri di dusun Kumbung Desa Kuripan Utara Wilayah Kerja Puskesmas

\section{DISKUSI}

\section{A. Karakteristik Responden remaja putri .}

1. Umur

Berdasarkan hasil penelitian dari 30 responden sebagian besar berumur 17-19 tahun sebanyak 14 orang (46,7\%). Remaja yang berumur 17-19 tahun, disebut sebagai "masa
Kuripan Tahun 2021.dan Berdasarkan hasil uji Wilcoxson diperoleh hasil nilai signifikan adalah 0,000 . Nilai $p<0,05$ maka dapat disimpulkan bahwa ada perbedaan yang signifikan antara sikap remaja putri sebelum dan sesudah diberikan pendidikan kesehatan menggunakan media video dan alat peraga tentang personal hygiene masa menstruasi sehingga ada pengaruh pendidikan kesehatan menggunakan media video dan alat peraga tentang personal hygiene masa menstruasi terhadap sikap remaja putri di Dusun Kumbung, Desa Kuripan Utara Wilayah Kerja Puskesmas Kuripan Tahun 2021.

remaja akhir" ditandai dengan persiapan untuk peran sebagai orang dewasa, termasuk klarifikasi dari tujuan pekerjaan dan internalisasi suatu sistem nilai pribadi. Bertambahnya usia seseorang, memberikan konsekuensi berupa terjadinya perubahan aspek fisik dan psikologis sehingga taraf berpikir seseorang yang semakin 
matang dan dewasa. Usia mempengaruhi terhadap daya tangkap dan pola pikir seseorang. Semakin bertambah usia akan semakin berkembang pula daya tangkap dan pola pikirnya, sehingga pengetahuan yang diperolehnya semakin membaik.

Menurut peraturan menteri kesehatan RI nomor 25 tahun 2014, remaja adalah penduduk dalam rentang usia 10-18 tahun dan menurut Badan Kependudukan dan Keluarga Berencana (BKKBN) rentang usia remaja adalah 10-24 tahun dan belum menikah. Remaja adalah generasi penerus bangsa. Masa remaja disebut juga sebagai periode perubahan, tingkat perubahan dalam sikap, dan perilaku selama masa remaja sejajar dengan perubahan fisik (Kemenkes RI, 2015).

Menurut Soetjiningsih (2007), remaja akan mengalami masa perkembangan, salah satunya perkembangan kognitif, perkembangan kognitif manusia sendiri berkembang secara bertahap, untuk remaja berusia 15-17 tahun akan masuk pada penyesuaian dari anak ke remaja. Pada stadium ini kemampuan berfikir remaja bersifat dedukatif- hipotesis. Kemampuan ini membuat remaja memikirkan dulu dan menganalisa suatu masalah dengan membuat strategi penyelesaian, sehingga pada usia ini remaja dapat menyikapi dengan tepat terkait pemanfaatan PIK KRR di sekolahnya dan memahami tentang kesehatan reproduksi.

\section{Pendidikan}

Tingkat pendidikan responden dalam penelitian ini bervariasi mulai dari SD, sekolah menengah pertama, sekolah menengah atas, sampai dengan perguruan tinggi. Dalam penelitian ini tingkat pendidikan responden dikategorikan kendala 4 kelompok. Dalam penelitian ini yang paling banyak responden berpendidikan SMA 18 orang $(60 \%)$ dan pendidikan dasar (SD dan SMP) sejumlah 12 orang $(40 \%)$. Semakin baik tingkat pendidikan seseorang maka akan semakin baik pola fikir yang terbentuk, sehingga responden dengan tingkat pendidikan baik akan semakin terbukB. terhadap hal-hal baru termasuk pengetahuan dan sikapnya dalam menjawab kuesioner tentang personal hygiene masa menstruasi.

Menurut Soekidjo (2003) pendidikan adalah upaya untuk memberikan pengetahuan sehingga terjadi perubahan perilaku positif yang meningkat, pendidikan akan memberikan pengetahuan sehingga terjadi perubahan perilaku dan tingkat pengetahuan lebih meningkat.

Tingkat pendidikan yang lebih tinggi akan memudahkan seseorang atau masyarakat untuk menyerap informasi dan mengimplementasikannya dalam perilaku dan gaya hidup sehari-hari khususnya dalam hal kesehatan, sehingga tingkat pendidikan formal dapat membentuk nilai bagi seseorang terutama dalam menerima hal baru (Muzaham, 2007). Semakin baik tingkat pendidikan seseorang maka akan semakin baik pola fikir yang terbentuk, sehingga pola piker yang baik tersebut akan membuat seseorang semakin terbuka terhadap hal-hal baru dan mampu menerima informasi dengan baik (Purwanto, 2011).

Penelitian Maidartati menyebutkan bahwa ada hubungan yang signifikan antara pengetahuan dengan perilaku vulva hygiene pada saat menstruasi pada remaja putri. Pengetahuan merupakan hasil dari "tahu" yang terjadi setelah orang melakukan penginderaan terhadap suatu obyek tertentu. Pengetahuan dapat diperoleh dari pendidikan, pengalaman diri dan orang lain, media massa maupun lingkungan. Pengetahuan atau koognitif merupakan domain yang sangat penting untuk terbentuknya tindakan seseorang.

Hasil penelitian menunjukkan sebelum diberikan pendidikan kesehatan dengan metode peer group sebanyak $33,8 \%$ siswi memiliki tingkat pengetahuan tentang personal hygiene saat menstruasi pada kategori kurang baik dan $50 \%$ sikap kurang mendukung. Namun, setelah diberikan pendidikan kesehatan dengan metode peer group terjadi peningkatan baik pada tingkat pengetahuan dan sikap yaitu sebanyak $98,5 \%$ siswi memiliki tingkat pengetahuan tentang personal hygiene saat menstruasi pada kategori baik dan 94,1\% memiliki sikap mendukung.

\section{Tingkat Pengetahuan Remaja Putri Sebelum dan Sesudah Diberikan Pendidikan Kesehatan.}

Berdasarkan hasil penelitian sebelum diberikan pendidikan kesehatan didapatkan bahwa remaja putri di Dusun Kumbung banyak yang memiliki tingkat pengetahuan dalam kategori cukup yaitu sebanyak 18 orang $(60 \%)$. 
Dan sesudah diberikan pendidikan kesehatan didapatkan bahwa remaja putri di Dusun Kumbung banyak yang memiliki tingkat pengetahuan dalam kategori baik yaitu sebanyak 29 orang $(97 \%)$.

Menurut Notoatmodjo (2003) pengetahuan atau kognitif merupakan domain yang sangat penting untuk terbentuknya suatu persepsi seseorang. Tingkat pengetahuan seseorang juga mempengaruhi persepsi dan perilaku individu, yang mana makin tinggi pengetahuan seseorang maka makin baik menafsirkan sesuatu.

$$
\text { Menurut Notoatmodjo }
$$
pengetahuan merupakan hasil dari tahu, dan ini terjadi setelah orang melakukan pengindraan terhadap suatu obyek tertentu. Pengindraan terjadi melalui panca indera manusia, yakni indera pengelihatan, pendengaran, penciumanC. rasa dan raba. Sebagian besar pengetahuan manusia diperoleh melalui mata dan telinga.

Menurut Susilo (2011), pendidikan kesehatan adalah upaya menerjemahkan apa yang telah diketahui tentang kesehatan kedalam perilaku yang diinginkan ataupun masyarakat melalui proses pendidikan.

Menurut Susilo (2011), pendidikan kesehatan adalah suatu proses perubahan pada diri manusia yang ada hubungannya dengan tercapainya tujuan kesehatan perorangan dan masyarakat.

Berdasarkan hasil penelitian yang dilakukan oleh Dian Erika Purnama (2013) yang berjudul "Efektifitas Pendidikan Kesehatan Terhadap Tingkat Pengetahuan Remaja Perempuan Tentang Pencegahan Keputihan Di SMK YMJ CIPUTAT" didapatkan hasil pendidikan kesehatan dengan metode ceramah memiliki efektifitas yang besar dalam meningkatkan pengetahuan mengenai pencegahan keputihan dengan nilai eta squared 0,468 .

Berdasarkan hasil penelitian yang dilakukan oleh Nurmaliza dkk. (2018) yang berjudul "Hubungan Tingkat Pengetahuan Remaja Putri Terhadap Personal Hygiene saat Menstruasi di SMA NEGERI 3 PEKANBARU TAHUN 2018". Dari hasil penelitian dapat dilihat bahwa remaja putri yang tingkat pengetahuan terhadap personal hygiene saat menstruasi baik 80 orang (68.4\%). Dan remaja putri yang tingkat pengetahuannya baik dengan personal hygiene saat menstruasi rendah ada 37 orang $(31.6 \%)$ sedangkan remaja putri yang tingkat pengetahuan rendah dan personal hygiene saat menstruasi baik 1 orang (33.3\%), dan remaja putri yang tingkat pengetahuan terhadap personal hygiene saat menstruasi rendah 2 orang $(66.7 \%)$. Dari hasil perhitungan menggunakan uji chi-square, hasil Pvalue yang digunakan adalah uji fisher's exact test (0.246) dan nilai $\alpha(0.05)$ ini menunjukan bahwa nilai Pvalue lebih besar dari nilai $\alpha(0.246>0.05)$, maka dapat disimpulkan bahwa tidak ada hubungan yang signifikan secara stastik antara tingkat pengetahuan terhadap personal hygiene saat menstruasi di SMA Negeri 3 Pekanbaru Tahun 2018.

\section{Sikap remaja Putri sebelum dan sesudah diberikan pendidikan kesehatan}

Berdasarkan hasil penelitian Sebelum diberikan pendidikan kesehatan didapatkan bahwa remaja putri di Dusun Kumbung banyak yang memiliki sikap dalam kategori positif yaitu sebanyak 19 orang (63\%). Dan sesudah diberikan pendidikan kesehatan didapatkan bahwa remaja putri di Dusun Kumbung banyak yang memiliki sikap dalam kategori positif yaitu sebanyak 27 orang $(90 \%)$.

Menurut Fishbein dalam Ali (2006: 141)" sikap adalah predisposisi emosional yang dipelajari untuk merespons secara konsisten terhadap suatu obyek ". Sedangkan menurut Secord dan Backman dalam Saifuddin Azwar (2012:88) " sikap adalah keteraturan tertentu dalam hal perasaan (afeksi), pemikiran (kognitif), dan predisposisi tindakan (konasi) seseorang terhadap suatu aspek di lingkungan sekitarnya".

Pendidikan kesehatan adalah suatu upaya menyebarluaskan atau memberikan informasi mengenai kesehatan yang bertujuan agar masyarakat berprilaku sesuai dengan nilai-nilai kesehatan (Notoatmodjo, 2005).

Soekidjo (2003) juga mengemukakan bahwa pendidikan kesehatan pada hakekatnya adalah suatu kegiatan atau usaha untuk menyampaikan pesan kesehatan pada masyarakat, kelompok, dan individu dengan harapan adanya perubahan perilaku yang baik.

Berdasarkan penelitian yang dilakukan oleh Nicky Antika Putri dkk. (2014) yang berjudul 
"Hubungan Pengetahuan dan Sikap Terhadap Perilaku Personal Hygiene Mentruasi" didapatkan hasil penelitian, berdasarkan dari hasil analisis bivariat hubungan antara sikap terhadap perilaku personal hygiene pada saą. menstruasi menunjukkan bahwa, responden dengan sikap baik dan perilaku personal hygiene pada saat mentruasi nya baik di SMP Patriot sebesar 23 siswi $(79,31)$, sedangkan responden dengan sikap kurang baik dan perilaku personal hygiene pada saat mentruasinya kurang baik sebesar 58 siswi (79,5\%). Hasil uji statistik diperoleh $\mathrm{p}=0,000$ dalam hal ini $\mathrm{p}<0,05$ maka dapat disimpulkan ada hubungan antara sikap terhadap perilaku personal hygiene pada saat mentruasi di SMP Patriot Kranji Tahun 2014. Dari hasil analisis diperolah pula nilai $\mathrm{OR}=$ 14,822 yang artinya siswi yang bersikap kurang baik terhadap personal hygiene pada saat mentruasi mempunyai peluang 14,822 kali berperilaku kurang baik dibanding sisiwi yang bersikap baik terhadap personal hygiene pada saat mentruasi.

Berdasarkan penelitian yang dilakukan oleh Umi Narsih (2021) yang berjudul "Keyakinan dan Sikap Remaja Putri Berhubungan dengan Perilaku Personal Hygiene Saat Menstruasi" didapatkan hasil bahwa ada kecenderungan semakin positif sikap remaja putri tentang personal hygiene maka akan semakin baik perilaku personal hygiene remaja putri saat menstruasi. Hasil uji statistik chi-square diperoleh nilai $\mathrm{p}$-value $=0.000$ dengan $\alpha=0.05$. Dengan demikian ada hubungan antara sikap dengan perilaku personal hygiene remaja putri saat menstruasi.

A. Analisis Pengaruh Pendidikan Kesehatan Menggunakan Media Video dan Alat Peraga Terhadap Tingkat Pengetahuan dan Sikap Remaja Putri Tentang Personal Hygiene Masa Menstruasi di Dusun Kumbung Kuripan Utara.

1. Analisis Pengaruh Pendidikan Kesehatan Menggunakan Media Video dan Alat Peraga Terhadap Tingkat Pengetahuan Remaja Putri Tentang Personal Hygiene Masa Menstruasi di Dusun Kumbung Kuripan Utara.

Berdasarkan hasil penelitian bahwa hasil uji statistik diperoleh nilai $p$ value $=0,000$ atau $p<\alpha$ $=0,05$ pada variabel yang diteliti yaitu tingkat pengetahuan remaja putri. Sehingga dari hasil uji statistik menyimpulkan terdapat pengaruh pendidikan kesehatan menggunakan media video dan alat peraga terhadap tingkat pengetahuan remaja putri tentang personal hygiene masa menstruasi di Dusun kumbung.

Analisis Pengaruh Pendidikan kesehatan Menggunakan Media Video dan Alat Peraga Terhadap Sikap Remaja Putri Tentang Personal Hygiene Masa Menstruasi di Dusun Kumbung Kuripan Utara.

Berdasarkan hasil penelitian bahwa hasil uji statistik diperoleh nilai $p$ value $=0,000$ atau $p<\alpha$ $=0,05$ pada variabel yang diteliti yaitu sikap remaja putri. Sehingga dari hasil uji statistik menyimpulkan terdapat pengaruh pendidikan kesehatan menggunakan media video dan alat peraga terhadap sikap remaja putri tentang personal hygiene masa menstruasi di Dusun Kumbung Kuripan Utara.

Menurut Rusman (2012), kelebihan video yaitu dapat memberikan pesan yang dapat diterima lebih merata oleh siswa, sangat bagus menerangkan suatu proses, mengatasi keterbatasan ruang dan waktu, dapat diulang atau dihentikan sesuai kebutuhan, dan memberikan kesan yang mendalam, dapat mempengaruhi sikap siswa.

Menurut Maryam (2014), menentukan alat peraga penyuluhan bertujuan membantu atau menunjang agar pesan yang disampaikan mudah dan cepat diterima oleh sasaran. Alat bantu peragaan yang dipakai juga bergantung tujuan, materi pesan, dan metode yang digunakan. Misalnya, untuk metode ceramah dapat menggunakan alat bantu, seperti leaflet, poster, booklet dan sebagainya. Untuk metode demonstrasi alat bantu peragaan yang dapat digunakan, misalnya gambar (potret), leaflet, alat demonstrasi (bahan,peralatan). Misalnnya penyuluhan tentang cara perawatan payudara yang benar, alat bantu peragaannya adalah phantom payudara agar sasaran dapat melihat benar-benar bagaimana mempraktikkan dengan benar cara perawatan payudara.

Berdasarkan hasil penelitian yang dilakukan oleh Urrahmah, Aulia (2019) yang berjudul "Pengaruh Media Audio Visual Terhadap Pengetahuan dan Sikap Personal Hygiene Menstruasi Pada Santri Di Pondok Pesantren Al Muna 2 Bantul" didapatkan hasil pengetahuan personal hygiene menstruasi sebelum diberikan edukasi kesehatan dengan media audiovisual, 
sebanyak 18 orang $(51,4 \%)$ santri putri memiliki pengetahuan yang baik dan meningkat menjadi 23 orang $(65,7 \%)$ setelah diberikan pendidikan kesehatan tentang personal hygiene menstruasi dengan media audio visual, sedangkan sikap personal hygiene menstruasi sebelum diberikan pendidikan kesehatan dengan media audio visual, sebanyak 19 orang (54,3\%)santri putri memiliki sikap positif dan meningkat menjadi 21 orang $(60,0 \%)$ setelah diberikan edukasi kesehatan dengan media audio visual. Dengan demikian terdapat pengaruh media audio visual terhadap peningkatan pengetahuan dan sikap personal hygiene menstruasi pada santri putrid di pondok pesantren Al Muna 2 Bantul.

\section{Simpulan}

Dari hasil penelitian yang telah dilakukan didapatkan hasil karakteristik respondenberdasarkan umur didapatkan hasił. bahwa responden terbanyak adalah yang berumur 17-19 tahun berjumlah 14 orang $(46,7 \%)$. Dan karakteristik responden berdasarkan pendidikan didapatkan hasil pendidikan responden terbanyak adalah pendidikan Menengah (SMA) sejumlah 18 orang. $(60 \%)$.

Dari hasil penelitian yang telah dilakukan sebelum diberikan pendidikar. kesehatan didapatkan bahwa remaja putri di Dusun Kumbung banyak yang memiliki tingkat pengetahuan dalam kategori cukup yaitu sebanyak 18 orang $(60 \%)$. Dan sesudah diberikan. pendidikan kesehatan didapatkan bahwa remaja putri di Dusun Kumbung banyak yang memiliki tingkat pengetahuan dalam kategori baik yaitu sebanyak 29 orang (97\%).

Dan hasil penelitian yang telah dilakukan sebelum diberikan pendidikan kesehatan didapatkan bahwa remaja putri di Dusun Kumbung banyak yang memiliki sikap. dalam kategori baik yaitu sebanyak 19 orang $(63 \%)$. Dan sesudah diberikan pendidikan kesehatan didapatkan bahwa remaja putri di Dusun Kumbung banyak yang memiliki sikap. dalam kategori positif bertambah menjadi 27 orang $(90 \%)$.

Terdapat pengaruh pendidikan kesehatan menggunakan media video dan ala8. peraga terhadap tingkat pengetahuan remaja putri tentang personal hygiene masa menstruasi di Dusun Kumbung, bahwa hasil uji statistic diperoleh nilai $\mathrm{p}$ value $=0,000$ atau $\mathrm{p}<\alpha=0,05$ pada variabel yang diteliti yaitu pengetahuan dan sikap remaja putri.

\section{Ucapan Terima Kasih}

Ucapan Terima Kasih Penulis Sampaikan kepada remaja putri yang menjadi responden penelitian ini serta semua pihak yang telah membantu khususnya pada bidan koordinator, bidan desa dan kader wilayah kerja UPT BLUD Puskesmas Kuripan yang telah membantu sehingga penelitian ini bisa terlaksana sesuai dengan yang direncanakan.

\section{DAFTAR PUSTAKA}

stri Aulia Fitri, 2018, Skripsi Pengaruh Penyuluhan Menggunakan Media Video Terhadap Tingkat Pengetahuan dan Sikap Remaja Awal Tentang Perubahan Fisik Masa Pubertas Dilingkungan Rembiga Timur Kelurahan Rembiga Wilayah Kerja Puskesmas Selaparang tahun 2018 , Mataram.

asniati Andi, dkk. 2020, Pengaruh Vidio Learning Multimedia Terhadap Pengetahuan, Sikap dan perilaku Menstrual Hygiene pada Remaja Putri. Makasar

asha Shindy Fajriani, 2019. Skripsi Pengaruh Pendidikan Kesehatan Terhadap Posisi dan Perlekatan Saat Menyusui Pada Ibu Post Partum Normal Di RSUD Kota Mataram Tahun 2019. Mataram

andayani lisa, dkk. 2020. Pengaruh edukasi Melalui Media Vidio dan Leaflet Terhadap Perilaku Personal Hygiene Pada Masa Menstruasi Remaja Di SMPN 2 Toili Kec. Mailong Kab. Banggai. Banggai.

arsih Umi, dkk. 2021. Jurnal kesehatan Keyakinan dan Sikap Remaja Putri Berhubungan dengan Perilaku Personal Hygiene Saat Menstruasi. Makasar

i Wayan Rempiyanti, 2018. Skripsi Hubungan Pengetahuan dan Sikap Ibu Bekerja Terhadap Asi Perah Dengan Praktik Pemberian Asi Ekslusif di Wilayah Kerja Puskesmas Karang Pule, Mataram.

urmaliza, dkk. 2019 Jurnal Hubungan Tingkat Pengetahuan Remaja Putri Terhadap Personal Hygiene Saat Menstruasi di SMA NEGERI 3 PEKANBARU TAHUN 2018. Pekanbaru

utri Nicky Antika, dkk 2014. Jurnal Hubungan 
Pengetahuan dan Sikap Terhadap perilaku Personal Hygiene Menstruasi. Jakarta Selatan.

9.

atnasari,dkk, 2019, Pengaruh Peer Education Terhadap2. Pengetahuan Personal Hygiene Masa Manstruasi Remaja Awal Di Pondok Pesantren Puteri Kota Makassar

10.

ofi'ah Siti, dkk. 2017, Efektifitas Pendidikan Kesehatan Metode Peer Group Terhadap Tingkat Pengetahuan Dan Sikap Personal hygiene Saat Menstruasi. Jurnal Ilmiah3. Bidan.

11.

usianti Novi exta ana ,2019,. Pengaruh Pendidikan Kesehatan Tentang Personal Hygiene Saat Menstruasi
Dengan Metode Audio Visual Terhadap Pengetahuan Remaja Putri Di MTS AL-MAAR Kabupaten Semarang. Unggaran, Makasar $\mathrm{R}$

ukma Nurhaliza, 2018 Skripsi Perbedaan Pengetahuan Tentang Kesehatan Reproduksi dan Sikap Remaja Terhadap Seks Pranikah dan PełRikahan Usia Dini Berdasarkan Pemanfaatan PIK KRR Di SMAN 5 Mataram Tahun 2018, Mataram

unianti 2015 .Skripsi Hubungan Pengetahuan Tentang keputihan dan Sikap Personal Hygiene Terhadap Kejadian Flour Albus (keputihan) Pada Mahasiswi Keperawatan UIN Alauddin Makasar tahun 2015 . Makasar 